\title{
LA BANCA CENTRAL COLOMBIANA EN 2003-2013
}

La banca central colombiana en una década de expansión, 2003-2013, José Antonio Ocampo, Jonathan Malagón

y Juan Sebastián Betancur, Bogotá, Universidad Externado de Colombia, 2015, 194 páginas

Salomón Kalmanovitz*

W xisten pocos trabajos sobre banca central en Colombia, y el esEtudio de ese tema de política pública tan importante se limita a los economistas especializados en finanzas. José Antonio Ocampo ha tomado la iniciativa de debatir la política monetaria del Banco de la República en la primera década del siglo xxi, junto a Jonathan Malagón y Juan Sebastián Betancur, ambos solventes no solo en el estudio del sector financiero sino de la macroeconomía nacional. Su dictamen sobre la política monetaria es bastante positivo pero hacen objeciones a la política o falta de política cambiaría del banco.

Los autores de este libro hacen un balance de la política monetaria del banco central colombiano en una fase que combinó una fuerte expansión económica con una revaluación de la moneda que ayudó a reducir la inflación. Rescatan la orientación contra cíclica de la junta del banco que contribuyó a sofocar la alta inflación de 2007, asociada a un fuerte crecimiento y a una política fiscal expansiva, y propició la recuperación económica después de la crisis financiera del Atlántico Norte.

Para ellos, las razones para el cambio del régimen monetario estuvieron asociadas a las inflaciones moderadas (en comparación con la alta inflación padecida en otros países latinoamericanos) que persistieron entre 1970 y 1999. La indexación de los precios fundamentales de la economía, en particular de la tasa de cambio -en un régimen que obligaba al banco central a adquirir reservas internacionales en

* Profesor emérito de la Universidad Jorge Tadeo Lozano, Bogotá, Colombia, [salomon.kalmanovitz@utadeo.edu.co]. Fecha de recepción: 26-08-2016, fecha de modificación: 3-09-2016, fecha de aceptación: 20-10-2016. Sugerencia de citación: Kalmanovitz, S. "La banca central colombiana en 2003-2013", Revista de Economía Institucional 18, 35, 2016, pp. 353-358. Dor: http://dx.doi.org/10.18601/01245996. v18n35.22. 
cuantías difíciles de esterilizar-, fue la causa principal de los excesos de demanda agregada. Se proporcionó crédito privado con base en la creación primaria de dinero y su asignación administrativa. Y, además, mencionan la tasa de interés, indexada al UPAC y los salarios, cuyos montos se fijaban con base en la inflación anterior, como factores que perpetuaban la inflación hacia el futuro. Pero olvidan que el financiamiento del gobierno por parte del banco central, especialmente durante los gobiernos de Belisario Betancur y Virgilio Barco, también incidió en el aumento de la inflación, sobre todo en 1990, cuando superó la cota del 30\%, y en la reducción de la tributación ${ }^{1}$; la monetización de la cuenta especial de cambios también era emisión pura a favor del gobierno. Todos esos elementos explican el arraigo de la inflación.

La reforma de los años noventa hizo posible que un banco central independiente enfrentara cada uno de estos problemas. La tasa de cambio pasó a deslizarse dentro de una banda que se ajustó en varias ocasiones, hacia abajo o hacia arriba, desligándola del nivel de precios interno, para que flotara libremente después de la crisis de 1998-1999. La tasa de interés se pudo desligar del nivel de precios una vez se redujo su nivel a un dígito, mientras que los salarios reales aumentaron gradualmente por el descenso sistemático de la inflación.

Los autores reconocen que la política monetaria logró reducir la inflación a niveles internacionales, pero aducen que no existió una política cambiaria que impidiera los incidentes de aguda revaluación hasta 2014, seguidos de una devaluación desproporcionada luego de esa fecha. Ocampo y sus coautores insisten en que el banco central colombiano habría podido aplicar una política cambiaria más activa para impedir esta revaluación del peso, tan dañina para los sectores transables de la economía:

el banco central no fue efectivo en contener el acentuado proceso de apreciación cambiaria y, de hecho, la tasa de cambio no ha sido una variable relevante a la hora de tomar decisiones de política monetaria [...] no [evitó], por lo tanto, que el peso colombiano se transformara en una de las monedas más fuertes del mundo (p. 130).

¿Qué habría podido hacer el banco, y que no hizo? ¿Enfrentar al gobierno para que no se siguiera endeudando tan alegremente? Se debe

\footnotetext{
${ }^{1}$ El recurso a la emisión para financiar al gobierno coincidió con la reforma tributaria de 1986 que eximió a los dueños de las empresas de pagar impuestos sobre sus dividendos, aduciendo una supuesta doble tributación. Entre 1984 y 1988 el Banco de la República le prestó al gobierno recursos equivalentes al 20,5\% del рів (Kalmanovitz, S. y M. Avella. "Barreras del desarrollo financiero: las instituciones monetarias colombianas", Revista del Banco de la República 851, septiembre de 1998).
} 
recordar que hizo comentarios y recomendaciones que los gobiernos de Uribe y Santos pasaron por alto.

A pesar de que los autores hacen gala de cierto virtuosismo econométrico para probar sus hipótesis, pecan porque omiten variables fundamentales que afectan el nivel de la tasa de cambio. Cabe advertirles que no solo de econometría vive el homo oconomicus. Aceptan que el banco actuó para atemperar los movimientos de capital, pero insinúan que no fue suficientemente drástico para impedir los incidentes de aguda revaluación. Eso es difícil cuando hay bonanza externa, aumenta el endeudamiento en dólares del gobierno, hay exceso de gasto agregado y, por encima de todo, las tasas de interés de la economía estadounidense son cercanas a cero, lo que debilita el dólar y fortalece las demás monedas.

Lo que más sorprende es que no hayan considerado los equilibrios macroeconómicos básicos de ahorro e inversión, en especial el público, pero también el privado. Pues durante la década en cuestión las cuentas del gobierno central fueron negativas y se recurrió a un aumento considerable de la deuda externa e interna (que incentivó la llegada de inversión de portafolio). En plena bonanza externa, Colombia aumentó su endeudamiento de 20.000 millones de dólares en 2003 a 35.600 millones en 2013, lo que obviamente acentuó la revaluación del peso.

Gráfica 1

Balance primario del gobierno central

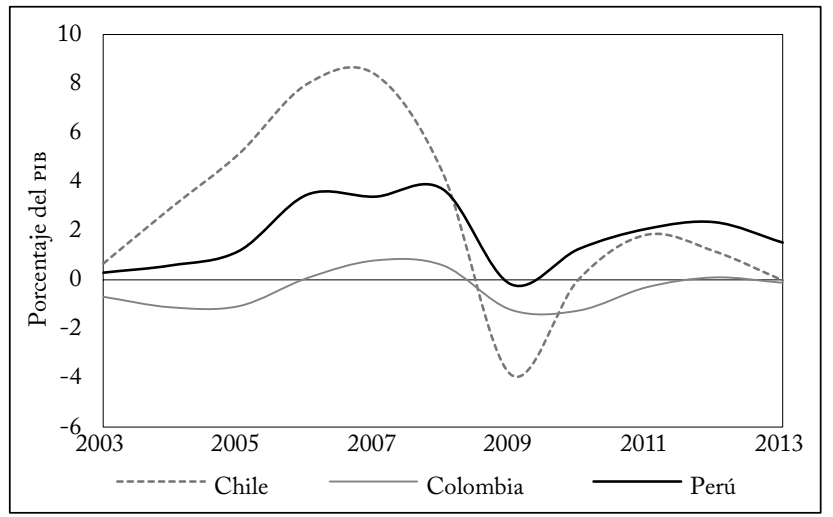

Fuente: Cepalstat.

La comparación con países que hicieron lo contrario - como Chile y Perú- desnuda las causas por las que sus monedas sufrieron revaluaciones y devaluaciones moderadas. Colombia no ahorró durante la 
bonanza de precios de las materias primas y sufrió una revaluación excesiva. Chile tenía una fórmula para que los excedentes generados cuando el precio del cobre superaba cierto umbral se ahorraran en cuentas fuera del país, las cuales llegaron a un $8 \%$ del рів. Perú tiene un régimen monetario dual que lo obliga a mantener una fuerte intervención en el mercado cambiario, pero también la financió con ahorros públicos que superaron el $3 \%$ del piB. En Colombia el faEP ahorró 4.268 millones de dólares entre 1996 y 2012, pero desahorró 3.294 millones en ese mismo lapso, dejando un saldo de $973 \mathrm{mi}-$ llones, insuficiente a todas luces para afectar el mercado cambiario. La comparación de la evolución de las tasas de cambio reales de los tres países entre 2003 y 2013 muestra una revaluación del 45\% en Colombia, mientras que la de Chile es del 18\% y la de Perú del 7\%.

Gráfica 2

Tasas de cambio reales

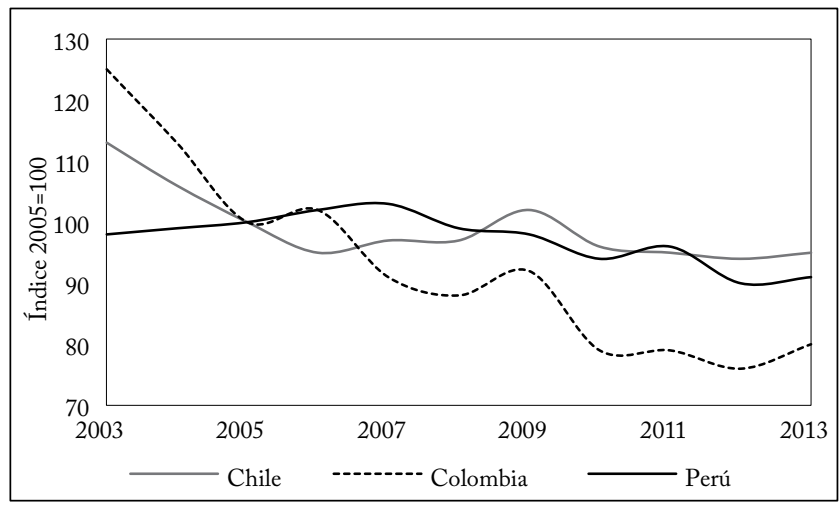

Fuente: Cepalstat.

¿Por qué el gobierno colombiano no hizo el ahorro requerido para sacar de la economía el exceso de divisas que se estaba recibiendo? La voracidad política aprovechó la bonanza para reducir impuestos en vez de aumentarlos, y se favoreció la inversión y el consumo privados, a costa de un ahorro que sirviera para enfrentar los años de vacas flacas. Quizás se pensó que la bonanza sería permanente. La inversión pública también se amplió y la parte que no se dilapidó en corrupción tal vez sea lo poco que quede de la bonanza. El exceso de inversión y consumo propició la alta inflación de 2007. El exceso de demanda y la revaluación también explican el déficit en cuenta corriente que se produjo en medio de la bonanza exportadora, algo que es inaudito. 
Gráfica 3

Deuda externa pública

(Miles de millones de dólares)

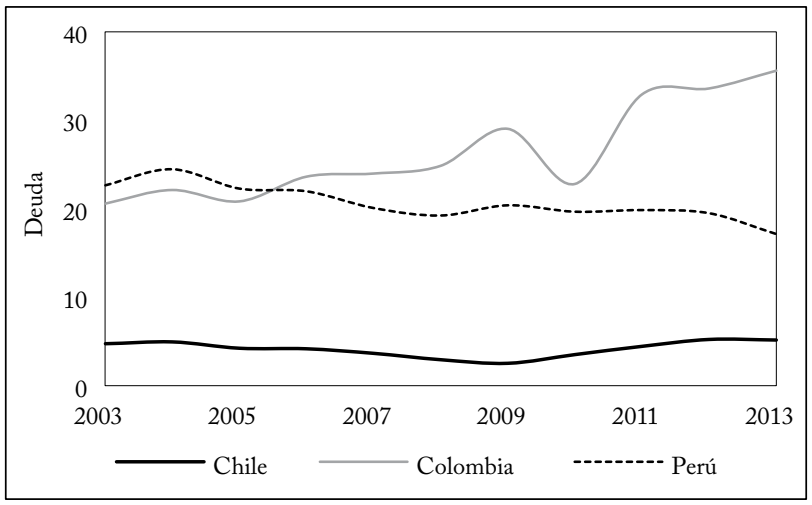

Fuente: Cepalstat.

Cuando terminó la bonanza a finales de 2014, la devaluación tenía que ser aguda, y la inflación colombiana alcanzó uno de los niveles más altos de América Latina. Los 43.000 millones de dólares de reservas que acumuló el banco central, equivalentes a 12 meses de importaciones, no son suficientes para una intervención agresiva en el mercado cambiario; y, además, se daría una mala señal a los agentes nacionales e internacionales si se queman divisas, mientras que el déficit en cuenta corriente alcanzaba un 6,6\% del piв en 2015.

\section{Gráfica 4}

Ingresos tributarios SPNF

(Porcentaje del PIв)

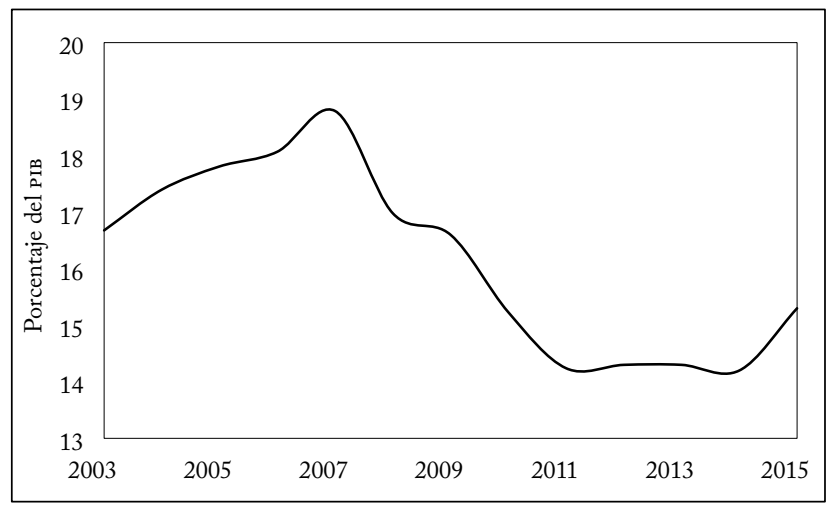

Fuente: Cepalstat. 
En las conclusiones los autores plantean lo siguiente:

Vale la pena preguntarse si el hecho de que el Banco de la República se haya caracterizado por la ejecución de una política de io (inflación objetivo) ortodoxa es un aspecto digno de orgullo en la actualidad, o si por el contrario es momento de migrar hacia un esquema en el que el banco central adopte un papel más activo en otras dimensiones que afectan el bienestar de la economía [...] (en el contexto del fin de la bonanza desde fines de 2014) debería hacer valer su alta credibilidad para dar un impulso a la actividad productiva, en un momento en que la política fiscal no está en capacidad de hacerlo (pp. 130 y 131).

Afirmar que el régimen inflación objetivo es ortodoxo es algo tendencioso porque los neoclásicos y monetaristas de Chicago lo rechazan. Quizá ha perdido efectividad en un periodo de desinflación y es necesario replantearlo. Su recomendación de promover el crecimiento en una coyuntura de alta inflación y grandes desequilibrios macroeconómicos, la cual implica que el Banco de la República puede despreocuparse de los desajustes externos, supone que se puede crecer a altas tasas con una capacidad de importar tan reducida. Obviamente, se necesitaría que el descalce se financiara externamente, algo muy difícil de lograr: con un volumen de inversión sujeto a que el gobierno haga una reforma tributaria y un ajuste adicional del gasto, es dudoso que una política monetaria expansionista tenga éxito; en cambio, puede contribuir a una crisis financiera de grandes proporciones. 